\title{
Características de la raza bovina Monchina y de su programa de recuperación
}

\author{
Barquín, F. ${ }^{\circledR}$; Crespo, M ${ }^{a}$ J. ${ }^{1}$; Vieito, A. ${ }^{1}$; Chomón, N. ${ }^{1}$; Fernández, M. ${ }^{2}$; Cañon, J. ${ }^{3}$ y De Argüello, S. ${ }^{4}$
}

'Centro de Selección y Reproducción Animal (CENSYRA). Consejería de Ganadería, Pesca y Desarrollo Rural. Gobierno de Cantabria. Torrelavega. Cantabria. España.

${ }^{2}$ Asociación Española de Criadores de Ganado Vacuno de Raza Monchina. Guriezo. Cantabria. España.

${ }^{3}$ Departamento de Producción Animal. Facultad de Veterinaria. Universidad Complutense. Madrid. España.

${ }^{4}$ Direccción General de Ganadería. Consejería de Ganadería Pesca y Desarrollo Rural. Gobierno de Cantabria. Santander. Cantabria. España.

PALABRAS CLAVE ADICIONALES

Estructura genética.

Información genealógica.

\section{RESUMEN}

La raza bovina Monchina es una raza autóctona de la Comunidad Autónoma de Cantabria, reconocida como raza en peligro de extinción. La utilización de información molecular mostró una raza dividida en tres ecotipos, con una elevada contribución a la diversidad genética del conjunto de razas bovinas de la Península lbérica, situándola genéticamente próxima a las razas Tudanca, Lidia, Betizú y Pirenaica. Por otro lado, la información genealógica, todavía con un reducido nivel de completitud, con un valor medio del número equivalente al de generaciones completas de 1,13, mostró una raza con un censo efectivo inferior al considerado por la FAO para poder garantizar la sostenibilidad de la diversidad genética a medio plazo (50 años).

The bovine Monchina breed: characteristics of the breed and of its conservation program

\section{SUMMARY}

The Monchina bovine breed is a local breed belonging to the Cantabria autonomous Spanish region, officially considered as endangered. The use of molecular information showed a breed structured into three genetically differentiated ecotypes, a high contribution to the genetic diversity of the Iberian Peninsula bovine set of breeds, and genetically close to the Tudanca, Lidia, Betizu and Pirenaica breeds. On the other hand, the depth of the available pedigree information is still low, with a mean equivalent to complete generations of 1.13 , the breed showed an effective population size lower than that considered by the FAO to preserve the medium-term sustainability of the genetic diversity (50 years).

INFORMACIÓN

Cronología del artículo.

Recibido/received: 09.05 .15

Aceptado/Accept: 22.04.16

Online: 15.09 .16

Correspondencia a los autores/Contact e-mail:

barquin_@@cantabria.es

\section{INTRODUCCIÓN}

La raza bovina Monchina es una raza autóctona de la Comunidad Autónoma de Cantabria, con presencia en el área de las Encartaciones de la provincia de Vizcaya, y en el Valle de Mena de la provincia de Burgos.

Las zonas en las que habitan son muy abruptas y están formadas en un $90 \%$ por plantaciones de eucalipto, bosques de matorral abrupto y con altos grados de inclinación en grandes áreas de su hábitat lo que obliga a esta raza no solo a pastorear sino también a ramonear brotes tiernos. Pasan todo el año en estas zonas, a veces de difícil acceso. Su gran hirsutismo y rusticidad permiten que con escasos alimentos soporten los rigores del clima atlántico que caracteriza la cornisa cantábrica. Pese a todas éstas características, no es extraño ver animales con una edad superior a los 20 años.

La Monchina se encuentra reconocida como raza autóctona en peligro de extinción en el Catálogo Oficial de Razas de Ganado Bovino de España, aprobado por R.D. 
2129/2008. El Libro Genealógico de la raza se aprueba por Orden de la Consejería de Ganadería Agricultura y Pesca del Gobierno de Cantabria de fecha 4/2/1999 (BOC 12/2/1999).

\section{MATERIAL Y MÉTODOS}

\section{CaRACTERÍSTICAS MORFOLÓGICAS DE LA RAZA}

Con un peso vivo alrededor de $400 \mathrm{~kg}$ y $1,30 \mathrm{~m}$ de alzada para los machos, $275 \mathrm{~kg}$ con 1,25 m de alzada para las hembras, y un temperamento arisco (acosados no tardan en embestir), fueron antiguamente utilizados en festejos taurinos. Actualmente se pueden encontrar tres tipos diferentes de capas: 1) Castaña oscura, denominada localmente envinada. Capa marrón muy oscura con mucosas negras; 2) Castaña clara, denominada avellana, con fondo marrón castaño claro, oscurecimientos centrífugos, y con mucosas oscuras; 3) Barriada, de aspecto atigrado y mucosas claras.

\section{CARACTERÍSTICAS DEL PROGRAMA DE RECUPERACIÓN Y FOMEN- TO DE LA RAZA}

La gestión del programa de recuperación se lleva a cabo mediante una comisión integrada por técnicos nombrados por la Administración y ganaderos designados por la Asociación de Criadores. Esta comisión ha procedido a una reclasificación de la totalidad de los animales inscritos en el Libro Genealógico utilizando las características morfo-estructurales, y patognomónicas de la raza, fundamentalmente los faneros y la coloración de las mucosas, dando lugar actualmente a dos categorías: Categoría $A$, son animales considerados puros, que cumplen con todas las exigencias del estándar racial. Sus descendientes tanto machos como hembras pueden ser inscritos en el Registro de Nacimientos del Libro Genealógico; Categoría B, son hembras con ligeros signos que evidencian la contaminación con sangres foráneas. Solamente se pueden inscribir en el Registro de Nacimientos del Libro Genealógico sus descendientes hembra.

En el año 2006 el Gobierno Cantabria crea en la Finca La Torquilla de su propiedad, un Centro de Testaje, del que salen seleccionados uno o dos sementales anualmente. En primer lugar se seleccionan animales con fecha de nacimiento entre los meses de marzo y abril anteriores a la entrada. En segundo lugar, puesto que en la actualidad no se dispone de méritos genéticos de todos los reproductores, se analiza el comportamiento fenotípico de la ascendencia de los animales. De entre los que pasen esta selección se eligen los 12 de menor parentesco medio. Durante los 10 meses siguientes se realiza un seguimiento exhaustivo del crecimiento de cada uno de los añojos, a través de un control mensual de peso. La media de edad de entrada a la finca es aproximadamente de 242 días y el peso medio en torno a los $135 \mathrm{~kg}$. Además, se procede a la extracción de semen, del que se almacenan 1000 dosis para el Programa de Con- servación (536 para el Banco de Germoplasma duplicado y el resto para su posible uso). Los machos que pasen el umbral de puntuación se devolverán a sus dueños, y se utilizarán como sementales mejorantes de la raza, pudiendo extraer la Administración semen de ellos para su banco de germoplasma, mientras que los sementales que no pasen las pruebas deberán ser sacrificados.

El empleo de las técnicas clásicas de la Zootecnia, como el registro de caracteres fenotípicos, el auxilio de técnicas de genética molecular, tanto para el análisis de diversidad genética y caracterización de la raza Monchina (Cañón et al., 2011, Martín-Burriel et al., 2011), como para el control genealógico y la disponibilidad de información genealógica, pueden considerarse herramientas útiles para acometer programas de recuperación y mantenimiento de poblaciones en peligro.

Finalmente, la disponibilidad de información genealógica, aunque todavía con una profundidad reducida, permitió llevar a cabo un análisis de la situación de la variabilidad genética presente y su proyección a medio plazo mediante la estimación de los principales parámetros poblacionales (Boichard, 2002).

\section{RESULTADOS Y DISCUSIÓN}

La información molecular mostró una diversidad génica esperada del $73 \%$ frente a la observada del $70 \%$, siendo esta diferencia significativa para un P-valor del $5 \%$. Por otro lado, se detectaron alelos exclusivos de la raza Monchina, siendo el ecotipo denominado $\mathrm{Ba}$ rriada el menos variable y, a su vez, el más diferenciado respecto a los de capa Avellana y Castaña. La posición relativa de esta raza en relación con el conjunto de razas bovinas autóctonas españolas es la de proximidad con las razas Tudanca, Lidia, Pirenaica y Betizú, resultando una de las razas que por su contribución a la diversidad genética resultó con una elevada prioridad (Cañón et al., 2011).

El tamaño de la población analizada a través de la información genealógica, o número total de animales en la base de datos, fue de 4976. De ellos, 2794 tienen a ambos padres conocidos. Si se consideran como población de referencia los individuos nacidos después de 2008, el pedigrí está constituido por 2794 animales, con un censo efectivo de ancestros contribuyendo a esta población de referencia de 479 , siendo el número de ancestros que explican el $50 \%$ de los genes de la población de referencia de 34 .

El censo efectivo de la raza varía en función de los elementos que se consideren en su cálculo, una de las estimaciones más fiables es la que tiene en cuenta el volumen de información genealógica disponible para cada animal. Hay que tener en cuenta que el censo efectivo suele dar resultados excesivamente optimistas cuando su cálculo está basado simplemente en los incrementos en endogamia individual sin tener en cuenta la cantidad 
Tabla I. Completitud genealógica en la raza bovina Monchina considerando la población en su conjunto (Completa) o sólo los animales de la población nacidos después del año 2008 (Referencia) (Pedigree completeness of the bovine Monchina breed when the whole population (Completa) is considered or only animals born after 2008 (Referencia)).

\begin{tabular}{ccc}
\hline & \multicolumn{2}{c}{ Completitud } \\
Generación & Completa & Referencia \\
\hline 1 & 0,578 & 0,825 \\
2 & 0,344 & 0,689 \\
3 & 0,148 & 0,410 \\
4 & 0,049 & 0,172 \\
5 & 0,010 & 0,041 \\
6 & 0,000 & 0,001 \\
\hline
\end{tabular}

de información genealógica utilizada en el cálculo de dicha endogamia individual. En el caso de la raza Monchina, el censo efectivo cuando se ajusta la endogamia por la información genealógica disponible es algo menos de la mitad $(25,1)$ que el censo efectivo de genomas fundadores $(58,6)$. Otras estimaciones del censo efectivo, proporcionan resultados entre 43 y 47 . También el censo efectivo calculado para la última generación es aproximadamente 47 , indicando que en la gestión llevada a cabo no es posible apreciar un deterioro de la variabilidad genética de esta raza, aunque esto siempre se debe interpretar con cautela cuando la información genealógica es poco profunda. Teniendo en cuenta la reducida profundidad de las genealogías (ver tabla I), con un valor medio para el número efectivo de genera- ciones de 1,13, tal vez haya que llamar la atención sobre la elevada endogamia de los animales consanguíneos $(12,5)$, así como el elevado porcentaje de animales con endogamias superiores a 6,25\% (77\%). Un factor positivo de la gestión es la evolución de la información genealógica registrada, que tiene su reflejo en el grado de completitud de las genealogías de la raza (tabla I).

El $58 \%$ de todos los animales que figuran en el Libro Genealógico tienen padres conocidos y el 34 \% tienen los 4 abuelos conocidos. Es evidente la tendencia positiva en el registro de la información genealógica ya que estos mismos datos referidos a la población de referencia (animales que han nacido después de 2008) son significativamente más elevados, 83 y 69 \% respectivamente. El promedio de completitud en las cinco generaciones ha pasado del 23 al $43 \%$.

\section{BIBLIOGRAFÍA}

Boichard, D. 2002. PEDIG: A Fortran package for pedigree analysis suited to large populations. Proc. $7^{\text {th }}$ World Congress of Genetics Applied to Livestock Production. Montpellier. France [CD-ROM]. Paper 28-13.

Cañón, J.; García, D.; Delgado, J.V.; Dunner, S.; Gama, L.T.; Landi, V.; Martín-Burriel, I.; Martínez, A.; Penedo, C.; Rodellar, C.; Zaragoza, P. and Ginja C. 2011. Relative breed contributions to neutral genetic diversity of a comprehensive representation of Iberian native cattle. Animal, 5: 1323-1334.

Martín-Burriel, I.; Rodellar, C.; Cañón, J.; Cortés, C.; Dunner, S.; Landi, V.; Martínez, A.; Ginja, C.; Gama, L.T.; Zaragoza, P. and Delgado, J.V. 2011. A global diversity and phylogenetic study of Iberian cattle using microsatellites. J Anim Sci, 89: 893-906. 